\title{
Grading the federal government on health care
}

\author{
Cite as: CMAJ 2017 January 9;189:E37. doi: 10.1503/cmaj.109-5355
}

$\mathbf{T}$ he federal Liberal government "has much to say to about health care" but what has it actually done to improve the health of Canadians since coming to power more than a year ago? According to the College of Family Physicians of Canada, the government has made some improvements, but progress has stalled in many areas of health care and, in a couple of instances, federal leadership has declined.

In a new paper - The Role of the Federal Government in Health Care, Report Card 2016 - the college compares the federal government's commitment to many areas of health care to its predecessor's performance in 2013. The college assigned three colour-grades - red (no involvement), yellow (somewhat involved), green (strong leadership) - to areas divided into five broad categories: putting patient care first, caring for the most vulnerable, having enough health care providers, establishing a vision for health care and measuring performance, and supporting health care research.

"We felt it would be appropriate and timely to refer back to things we thought were important three years ago, and are still important now, and see the level of federal leadership and commitment on these issues," said Dr. Francine Lemire, the college's executive director and chief executive officer. "We believe there have been some improvements in terms of commitment and engagement, but more remains to be done. Some of this may happen through the health accord and how it is negotiated."

Health care may be delivered at the provincial level but national standards are needed in some areas of health to ensure people in one part of Canada have the

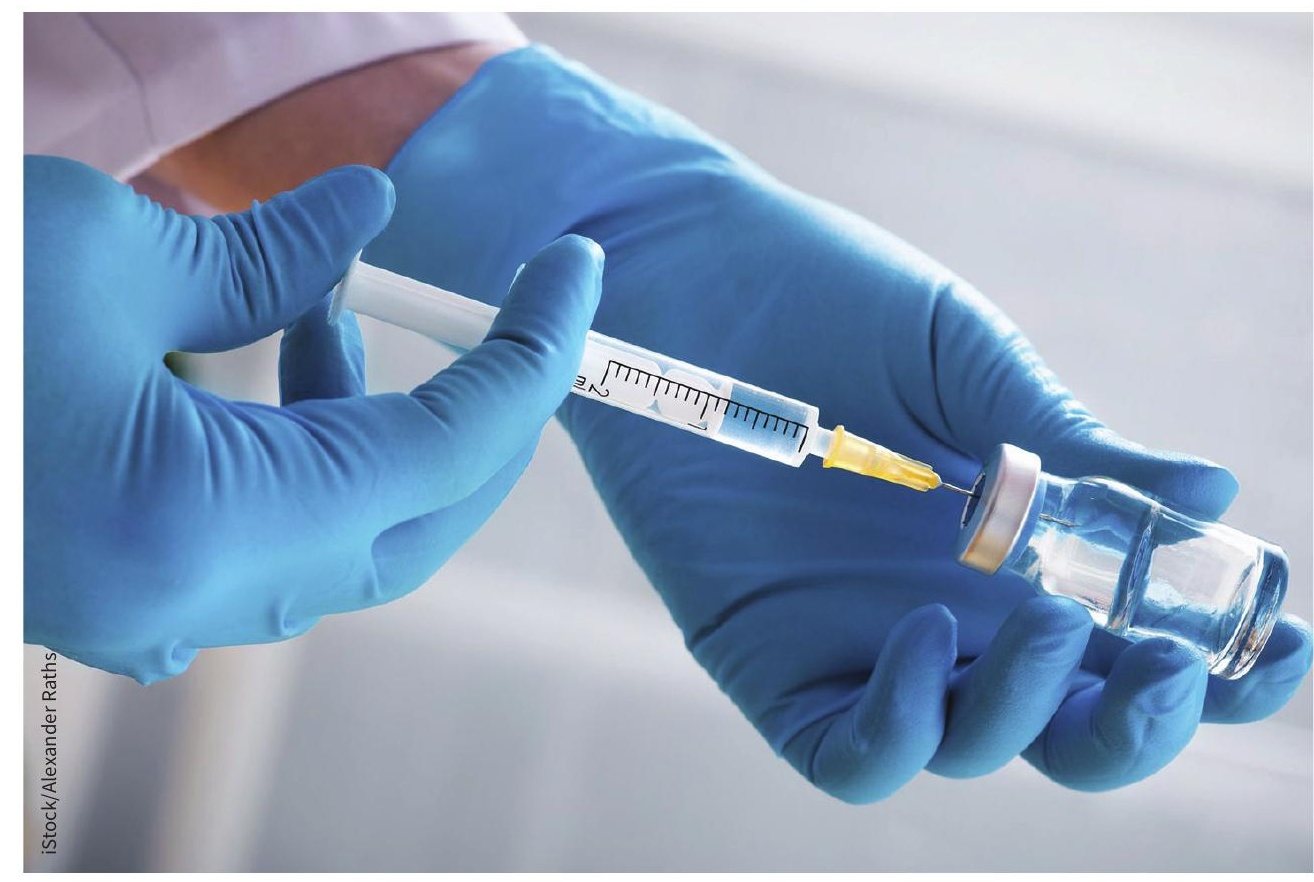

The federal government's commitment to immunization has improved since 2013, says new report.

same access to services as people in other parts, said Lemire. Areas where the federal government's engagement have improved since 2013 include a national immunization strategy, Indigenous health, a child and youth strategy, a national home care program, funding for health care research and a national poverty plan.

"The report card puts quite a bit of emphasis on social determinants of health, and if I had to pick one, I'd say that reducing poverty in Canada - developing a national poverty plan to decrease poverty - would be the one that could have the biggest impact," said Lemire.

According to the report, the government is less involved than in 2013 in two areas: tracking health workforce supply issues to ensure Canada has the right mix of health care providers, and providing timely access to care. The lack of timely access is a particularly pressing matter, suggested Lemire, and has the potential to trump other concerns if not addressed. Though these and other concerns remain, it may be too early to judge accurately the Liberal government's overall commitment to health care.

"We have to be realistic. The government has been in power for only a year, and it sounds like there is quite a bit of energy being dedicated to a new health accord, which will provide an opportunity to build in some deliverables," said Lemire. "We will likely explore this again, looking at performance, once the government has had a greater chance to get its teeth into this portfolio."

\section{Roger Collier, CMAJ}

